\title{
Unwelcome memento mori or best clinical practice? Community end of life anticipatory medication prescribing practice: A mixed methods observational study
}

Palliative Medicine 2022, Vol. 36(1) 95-104 (C) The Author(s) 2021 (c) (i)

Article reuse guidelines: sagepub.com/journals-permissions DOI: 10.1177/02692163211043382 journals.sagepub.com/home/pmj

(S)AGE

\author{
Ben Bowers ${ }^{1}$, Kristian Pollock ${ }^{2}$ and Stephen Barclay ${ }^{1}$
}

\begin{abstract}
Background: Anticipatory medications are injectable drugs prescribed ahead of possible need for administration if distressing symptoms arise in the final days of life. Little is known about how they are prescribed in primary care.

Aim: To investigate the frequency, timing and recorded circumstances of anticipatory medications prescribing for patients living at home and in residential care.

Design: Retrospective mixed methods observational study using General Practitioner and community nursing clinical records.

Setting/participants: 329 deceased adult patients registered with Eleven General Practitioner practices and two associated community nursing services in two English counties (30 most recent deaths per practice). Patients died from any cause except trauma, sudden death or suicide, between 4 March 2017 and 25 September 2019.

Results: Anticipatory medications were prescribed for $167 / 329$ (50.8\%) of the deceased patients, between 0 and 1212 days before death (median 17 days). The likelihood of prescribing was significantly higher for patients with a recorded preferred place of death (odds ratio [OR] 34; 95\% Cl 15-77; $p<0.001$ ) and specialist palliative care involvement (OR 7; 95\% $\mathrm{Cl} 3-19 ; p<0.001)$. For $66.5 \%$ of patients (111/167) anticipatory medications were recorded as being prescribed as part of a single end-of-life planning intervention. Conclusion: The variability in the timing of prescriptions highlights the challenges in diagnosing the end-of-life phase and the potential risks of prescribing far in advance of possible need. Patient and family views and experiences of anticipatory medication care, and their preferences for involvement in prescribing decision-making, warrant urgent investigation.
\end{abstract}

\section{Keywords}

Anticipatory prescribing, anticipatory medications, palliative medicine kit, terminal care, palliative care, mixed methods, end of life care, home palliative care, community nursing, general practice

\section{What is already known on this topic?}

- The prescribing of injectable anticipatory medications to provide symptom relief in the last days of life is recommended and widespread practice in a number of counties.

- There is limited research concerning the frequency, timing and context of prescriptions.

\section{What this paper adds?}

- Half (50.8\%) of 329 patients whose deaths were potentially predictable deaths were prescribed anticipatory medications, the timing of prescriptions ranging from 0 to 1212 days before death (median 17 days).

- Anticipatory medications were frequently prescribed as standardised drugs and doses, and often as part of a single endof-life care planning intervention.

- Patients' and family carers' involvement in prescribing decisions was unclear.

1Primary Care Unit, Department of Public Health and Primary Care, University of Cambridge, Cambridge, UK

${ }^{2}$ Nottingham Centre for the Advancement of Research into Supportive, Palliative and End of Life Care, School of Health Sciences, University of Nottingham, Nottingham, UK

\section{Corresponding author:}

Ben Bowers, Primary Care Unit, Department of Public Health and Primary Care, University of Cambridge, East Forvie Building, Robinson Way, Cambridge CB2 OSR, UK.

Email: bb527@medschl.cam.ac.uk 
Implications for practice, theory or policy

- Patient and family preferences for involvement in anticipatory medications prescribing decision-making and their experiences of care warrant urgent investigation.

- The presence of anticipatory medications for long periods of time may compromise patient safety unless robust systems are in place to review their continued appropriateness and safe use.

\section{Introduction}

Timely and effective symptom control in the last days of life is a key component in ensuring a comfortable death. ${ }^{1-6}$ In the UK, Australia, Canada, Norway and New Zealand, the individualised prescribing of injectable anticipatory medications, ahead of potentual need, for people approaching the end of life in the community is widely promoted to optimise symptom control in the last days of life at home and prevent unwanted hospital admissions. ${ }^{7-13}$ Anticipatory medications are kept in the home, where they are available to be administered by visiting nurses or doctors if the patient is unable to take oral medications and develops symptoms of pain, breathlessness, nausea and vomiting,

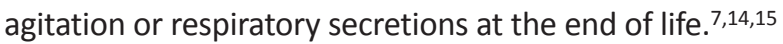

Although anticipatory prescribing is recommended practice in several countries ${ }^{8,9,12,13}$ there is inadequate evidence of its clinical effectiveness and limited research into the incidence and timing of prescriptions. ${ }^{7,8}$ Reported prescribing rates vary from up to $14 \%$ or $16 \%$ of predictable deaths in primary care populations in Australia and the UK $^{13,16}$ to $63 \%$ of patients receiving specialist palliative care input. ${ }^{17}$ Most published evidence relates to UK practice. ${ }^{7}$ Patients with advanced cancer appear more likely to receive prescriptions than those with non-cancer terminal conditions. ${ }^{11,18-20}$ The timing of prescribing to death is reported as ranging from a few days, ${ }^{11,19,20}$ several weeks ${ }^{15,17,19-21}$ to several months before death. ${ }^{22}$

The decision to prescribe anticipatory medications is multifaceted and little studied to date. Community nurses report they initiate anticipatory prescribing conversations with patients and families when they perceive that death is imminent, following which they prompt General Practitioners (GPs) to prescribe medications. ${ }^{15,23,24}$ Nurses find some GPs to be resistant to prescribing anticipatory medications ${ }^{18,23,25}$ while other GPs act on their requests to prescribe. ${ }^{13,23,24}$ Some GPs prefer to independently judge when to prescribe anticipatory medications, $10,20,22$ or to discuss intended care with patients themselves and prescribe drugs whilst their condition is stable. ${ }^{13,22}$ Prescribing decisions involve assessing patient and family willingness to have end-of-life care discussions, safety risks associated with prescribing strong opioids and how soon medications may be needed. ${ }^{15,20,22}$

GP and community nurse records provide useful observational data for understanding practice. Retrospective examination of routinely collected clinical data enables investigation of recorded activities and interactions such as prescribing while avoiding selection and recruitment biases that are a major difficulty in prospective studies of terminally ill populations. ${ }^{26,27}$

Our study aims were to investigate the frequency, timing and recorded circumstances of injectable end-of-life anticipatory medications prescribing for patients living at home and in residential care.

\section{Methods}

\section{Study design}

We carried out a retrospective mixed methods observational study of deceased patients recorded care using GP and community nursing held clinical records. ${ }^{28,29}$ Quantitative and qualitative analysis were used to provide detailed and complementary insights into practice. Reflecting the social constructionist paradigm, ${ }^{30}$ clinical records are selective and stylised clinician accounts rather than presenting only objective facts. ${ }^{31,32}$

The Cambridge Positive Ageing and Cambridge Palliative and End of Life Care Patient and Public Involvement (PPI) Groups supported the study throughout. Both groups advised on the research priorities, the acceptability of accessing deceased patient records without consent and the interpretation of key findings.

\section{Ethical approvals}

The South Cambridgeshire Research Ethics Committee granted ethics approval [Reference: 19/EE/0012]. The Health Research Authority's Confidentiality Advisory Group [19/CAG/0014] approved the processing of confidential patient information without patient consent: data were anonymised at the earliest opportunity.

\section{Study population and setting}

Participants were registered with eleven GP practices and two associated National Health Service Community Trusts providing community nursing services in two English counties. GP practices were purposively sampled from 21 practices expressing interest in participation, to obtain a maximum diversity sample in terms of patient list sizes (range 5500-43,000), geographical setting (two outer London practices, three urban, six rural town/villages) and practice population socioeconomic status (range third most deprived decile to the least deprived decile). 
Each practice identified the 30 most recent expected deaths of patients aged $18+$ years, who had been living at home or in residential care for at least 1 day in the last month of life and had died from any cause except trauma, sudden death or suicide. Patients living in nursing homes, with on-site trained nurses, were excluded as their care can differ considerably from those at home or in residential care. Patients who had previously indicated a wish not to be involved in research were excluded. Patients died between 4 March 2017 and 25 September 2019: one was excluded upon confirming their cause of death after data extraction, leaving a study population of 329 patients.

\section{Data sources and definitions}

The electronic GP records and electronic and paper community nursing records of the deceased patients were retrieved and examined between May 2019 and March 2020 by BB, an experienced community and palliative care nurse. Patient demographic and clinical characteristics, documented end-of-life planning discussions and decisions, summary of events in the 7 days preceding anticipatory medication prescribing, recorded prescribing contexts and decision-making and medication details were entered into a custom-built secure database (Supplemental Document 1). Relevant free text record entries were summarised. Cause and date of death were confirmed from GP practice held death certificate books or England's General Register Office.

Anticipatory medications were defined as one or more injectable medications prescribed ahead of need to be administered for symptom control in the last days of life. 7,14

\section{Data analysis}

Data analysis combined quantitative and qualitative analyses in a mixed methods approach. ${ }^{28,29}$ Categorical data are reported as frequencies and percentages and continuous data as median (interquartile range: IQR). The sample size of 330 patients was calculated a priori with a statistician to enable statistical analysis including Chi-square and Fisher's exact test and multivariable logistic regression models. ${ }^{29}$ Data analysis was performed using SPSS version 26: $p<0.05$ is considered statistically significant.

BB undertook qualitative analysis using inductive constant comparison incident-to-incident coding 28 of extracted data from the clinical records of all patients prescribed anticipatory medications focussing on end-of-life discussions, prescribing contexts and associated patient and family interactions, using NVivo version 12 . BB is a clinical academic and community palliative care nurse with experience of conducting qualitative analysis. Thematic patterns and variances in records, typologies of care and decisions in attributing significance to findings
Table 1. Demographics and clinical characteristics of deceased patients.

\begin{tabular}{lrl}
\hline Age range & $n$ & $(\%)$ \\
\hline $18-64$ & 50 & $(15.2)$ \\
$65-74$ & 63 & $(19.1)$ \\
$75-84$ & 92 & $(28.0)$ \\
$85+$ & 124 & $(37.7)$ \\
Gender male & 169 & $(51.4)$ \\
Usual place of care & & \\
$\quad$ Home & 299 & $(90.9)$ \\
Care home & 30 & $(9.1)$ \\
Ethnicity & & \\
$\quad$ White & 294 & $(89.4)$ \\
Other & 11 & $(3.3)$ \\
$\quad$ Not recorded & 24 & $(7.3)$ \\
Cause of death & & \\
Cancer: solid tumour & 130 & $(39.5)$ \\
Cancer: haematological malignancy & 6 & $(1.8)$ \\
Chronic heart disease & 41 & $(12.5)$ \\
Dementia & 15 & $(4.6)$ \\
Pneumonia & & $(14.6)$ \\
Chronic obstructive pulmonary disease & 26 & $(7.9)$ \\
Stroke & 13 & $(4)$ \\
Liver disease & 2 & $(0.6)$ \\
Acute heart disease & 3 & $(0.9)$ \\
Frailty of old age & 22 & $(6.7)$ \\
Other & 23 & $(7)$ \\
\hline & & \\
& & \\
& &
\end{tabular}

were discussed and refined with $\mathrm{KP}, \mathrm{SB}$ and both PPI groups. These iterative steps informed the interpretative analysis. ${ }^{28,33}$

\section{Results}

Most deceased patients were either aged between 75 and 84 years $(92 / 329,28 \%)$ or 85 years and older (124/329, $37.7 \%)$. The majority of deaths were from non-cancer conditions $(193 / 329,58.7 \%)$. However, the most frequently occurring cause of death was solid tumours. See Table 1.

In total, $167 / 329(50.8 \%)$ patients were prescribed anticipatory medications. There was a wide range of prescribing rates across the eleven GP practices, with a median of $14 / 30$ patients (46.7\%) (IQR $11-17 / 30$ patients) and range $7 / 30(23.3 \%)$ to $28 / 30(93.3 \%)$. There was a highly statistically significant association between the GP practice patients were registered with and whether they were prescribed anticipatory medications $(p<0.001)$. Patients who died from cancer were more likely to be prescribed medications (67.6\%) than those who died from non-cancer conditions (38.9\%) ( $p<0.001)$. See Table 2.

All statistically significant variables in the univariate analysis in Table 2 were entered into a multivariate regression analysis, which revealed that after adjustment for 
Table 2. Univariate analysis of relationships of patient characteristics and anticipatory medication prescribing.

\begin{tabular}{|c|c|c|c|}
\hline Patient characteristics & $\begin{array}{l}\text { Prescribed anticipatory } \\
\text { medications (167)/Total (329) }\end{array}$ & & \\
\hline Gender & & $X^{2}(D F=1)=0.503$ & $p=0.478$ \\
\hline Male & $89 / 169$ (52.7\%) & & \\
\hline Female & $78 / 160(48.8 \%)$ & & \\
\hline Age range & & $X^{2}(\mathrm{DF}=3)=1.345$ & $p=0.718$ \\
\hline $18-64$ & $24 / 50(48 \%)$ & & \\
\hline $65-74$ & $33 / 63(52.4 \%)$ & & \\
\hline $75-84$ & $43 / 92(46.7 \%)$ & & \\
\hline $85+$ & $67 / 124(54 \%)$ & & \\
\hline Ethnicity & & $X^{2}(\mathrm{DF}=2)=0.304$ & $p=0.859$ \\
\hline White & $150 / 294(51 \%)$ & & \\
\hline Other & $6 / 11(54.5 \%)$ & & \\
\hline Not Recorded & $11 / 24(45.8 \%)$ & & \\
\hline GP practice ID no. & & $X^{2}(\mathrm{DF}=10)=36.059$ & $p<0.001$ \\
\hline One & $13 / 30(43.3 \%)$ & & \\
\hline Two & $14 / 30(46.7 \%)$ & & \\
\hline Three & $14 / 30(46.7 \%)$ & & \\
\hline Four & $28 / 30(93.3 \%)$ & & \\
\hline Five & $19 / 29(65.5 \%)$ & & \\
\hline Six & $16 / 30(53.3 \%)$ & & \\
\hline Seven & $16 / 30(53.3 \%)$ & & \\
\hline Eight & $14 / 30(46.7 \%)$ & & \\
\hline Nine & $13 / 30(43.3 \%)$ & & \\
\hline Ten & $7 / 30(23.3 \%)$ & & \\
\hline Eleven & $13 / 30(43.3 \%)$ & & \\
\hline $\begin{array}{l}\text { Number of practice chronic disease } \\
\text { registers patient was on }\end{array}$ & & $X^{2}(\mathrm{DF}=4)=12.789$ & $p=0.012$ \\
\hline $0-1$ & $12 / 43(27.9 \%)$ & & \\
\hline $2-3$ & $64 / 128(50 \%)$ & & \\
\hline $4-5$ & $48 / 88$ (54.5\%) & & \\
\hline $6-7$ & $27 / 43(62.8 \%)$ & & \\
\hline $8-13$ & $16 / 27(59.3 \%)$ & & \\
\hline Usual place of residence & & $X^{2}(D F=1)=0.728$ & $p=0.393$ \\
\hline Care home & $13 / 30(43.3 \%)$ & & \\
\hline Home & $154 / 299$ (51.5\%) & & \\
\hline Cause of death & & $X^{2}(\mathrm{DF}=1)=26.452$ & $p<0.001$ \\
\hline Cancer & $92 / 136(67.6 \%)$ & & \\
\hline Non-cancer & 75/193 (38.9\%) & & \\
\hline DNACPR form completed & & Fisher's exact test & $p<0.001$ \\
\hline Yes & $163 / 227(71.8 \%)$ & & \\
\hline No & $4 / 102(3.9 \%)$ & & \\
\hline On GP practice palliative care register & & $X^{2}(\mathrm{DF}=1)=120.321$ & $p<0.001$ \\
\hline Yes & $135 / 168(80.4 \%)$ & & \\
\hline No & $32 / 161(19.9 \%)$ & & \\
\hline Received specialist palliative care & & $X^{2}(\mathrm{DF}=1)=86.166$ & $p<0.001$ \\
\hline Yes & $117 / 148(79.1 \%)$ & & \\
\hline No & $50 / 181(27.6 \%)$ & & \\
\hline Preferred place of death & & $X^{2}(\mathrm{DF}=1)=186.118$ & $p<0.001$ \\
\hline Recorded & $152 / 178(85.4 \%)$ & & \\
\hline Not recorded & $15 / 151(9.9 \%)$ & & \\
\hline
\end{tabular}

gender, age range, GP practice, number of chronic disease registers on, usual place of residence and cause of death, the likelihood of being prescribed anticipatory medications was significantly higher for patients with a recorded preferred place of death (OR 34; 95\% Cl 15-77; $p<0.001$ ) and for patients who had received specialist palliative care (OR 7; 95\% Cl 3-19; $p<0.001$ ) (Supplemental Document 2). Preferred place of death was included in the 
logistic regression model as the most theoretically sound marker of end-of-life planning; a completed Do Not attempt Cardiopulmonary Resuscitation (DNACPR) form and/or inclusion on the GP practice palliative care register was not always associated with a record of explicit end-oflife care planning.

\section{Recorded prescribing decision-making}

Anticipatory medications were frequently recorded as being prescribed as part of a single end-of-life planning consultation: for 111/167 (66.5\%) of patients prescribed medications, the prescription (or discussion concerning prescription) occurred during the same consultation when preferred place of death and/or cardiopulmonary resuscitation discussions were first recorded. There were three typologies of prescribing contexts. For $78 / 167$ (46.7\%) of patients, anticipatory medications were prescribed in the context of rapid deterioration; end of life was recorded as being imminent, with rapid deterioration of physical strength over a few days, escalating symptoms and reduced ability to eat or drink. Some patients then recovered and stabilised. The second prescribing context was clinical uncertainty; 17/167 (10.2\%) of patients were prescribed anticipatory medications in case their condition did not improve, alongside the prescription of oral antibiotics for potentially reversible infections:

6 days before death, GP visits the patient and records: 'Deterioration, taken to bed, refusing drinks for the last 1-2 days. Comfortable, responding to carers. . . Unclear if has a urine tract infection (UTI) or this is a pre-terminal event. . . Tried phoning family but no answer. Plan: Completed DNACPR form with agreement of carers. Issued anticipatory medications and oral antibiotics. Treat for UTI and encourage fluids'. Computer codes: preferred place of care and death is home, patient is 'aware of prognosis'. [Patient 91, GP Practice ID Four]

In contrast, $72 / 167$ (43.1\%) of patients were prescribed anticipatory medications as part of longer-term forward planning. This was when patients had a relatively stable physical function, but the focus of care had shifted to endof-life support:

292 days before death - GP visits the patient and records: 'Recently seen in hospital by oncology and has been told has extensive metastatic disease. For palliative care. Increasing weight loss. Mood stable despite of diagnosis and poor prognosis. Plan: anticipatory medications and chart done. Add to end-of-life care register'. Computer codes 'months prognosis' and 'aware of prognosis'. [Patient 287, GP Practice ID Nine]

Recorded patient and family involvement in decisions to prescribe anticipatory medications were variable. No prescribing conversations were recorded for $69 / 167$ of patients (41.3\%). For a few patients $(6 / 167,3.6 \%)$, it was recorded that they did not want to discuss their prognosis or consider that they were dying at the time of prescribing anticipatory medications; clinicians still documented a preferred place of care and death in records. These patients lived alone, and prescribing decisions were framed as being in their best interests:

27 days before death, GP visits patient and records: Three recent hospital admissions in the last month for congestive cardiac failure symptom management. 'Can barely get out of bed and needing carer visits four times a day. . . Does not want to discuss their prognosis... States wants active treatment and not wanting to engage in end-of-life care planning. . . Lives alone. . May need to go into palliative care mode swiftly. Plan: best set [prescribe] anticipatory medications now'. Computer codes: preferred place of care and death is home. [Patient 24, GP Practice ID One]

Patient and family involvement in decision-making was recorded for $71 / 167$ (42.5\%) of patients, the records focussing on whether they agreed with clinician decisions to prescribe anticipatory medications: 10/71 patients (6\%) were prescribed drugs prior to a visit or phone call to discuss prescribing. Most records concerning prescribing conversations were very brief, largely limited to reporting that families had been asked to collect the medications or patient/family agreement with prescribing decisions. More detailed anticipatory medication decision-making conversations were recorded when patients or families were concerned about possible symptoms (29/167, $17.4 \%)$. In a few cases $(5 / 167,3 \%)$, patient or families were recorded as not agreeing with a decision to prescribe anticipatory medications: three patients and one family were resistant to the idea of prescribing, and one patient was 'aggrieved' on discovering they had been prescribed medications without being asked. In these cases, clinicians recorded that it was in the patient's best interests to have anticipatory medications available and documented persuading them to accept prescriptions:

3 days before death, GP visits patient at home: 'Discussed DNACPR and patient does not want resuscitation. States would like to pass away peacefully. . . Discussed anticipatory medications. [Patient states] does not want or need any medications. Explained these medications were only for if in distress. . . [Patient] remained adamant that does not need them. . . Discussed each group of medication and intended benefit in detail. . . I advised that they might not need them, and we will of course adhere to their wishes, but we do not want them to suffer. . . Agreed to [having] them'. [Patient 115, GP Practice ID Four]

\section{Timing of prescribing}

Anticipatory medications were prescribed between 0 and 1212 days before death. Patients who died from cancer were prescribed medications a median of 21.5 days before death (IQR 7-42 days, range 0-375 days); for 
Table 3. Timing of anticipatory medications prescribing in days before death.

\begin{tabular}{|c|c|c|c|c|c|}
\hline GP practice ID no. & $n$ & Minimum & Maximum & Median & IQR \\
\hline One & $13 / 30$ & 0 & 375 & 17 & $9-78$ \\
\hline Two & $14 / 30$ & 2 & 47 & 6.5 & $4.5-28.25$ \\
\hline Three & $14 / 30$ & 2 & 374 & 17 & $8.5-36.75$ \\
\hline Four & $28 / 30$ & 0 & 615 & 12.5 & 3-95 \\
\hline Five & $19 / 29$ & 1 & 695 & 33 & $6-60$ \\
\hline Six & $16 / 30$ & 2 & 287 & 30 & $10-83.5$ \\
\hline Seven & $16 / 30$ & 1 & 158 & 22.5 & $6.5-50.5$ \\
\hline Eight & $14 / 30$ & 1 & 50 & 14 & $4.75-20.75$ \\
\hline Nine & $13 / 30$ & 1 & 292 & 13 & $3.5-67$ \\
\hline Ten & $7 / 30$ & 2 & 104 & 6 & $2-19$ \\
\hline Eleven & $13 / 30$ & 3 & 1212 & 25 & $7.5-48.5$ \\
\hline
\end{tabular}

those who died from non-cancer illnesses, medications were prescribed a median of 12 days before death (IQR 4-47 days, range 1-1212 days). Seven patients were prescribed anticipatory medications a year or more before death, of which six had a non-cancer diagnosis. The median prescribing timing was 17 days before death across the eleven GP practices, with range of median of 6-33 days between the practices. See Table 3.

\section{Clinicians prescribing medications}

For $71 / 167(42.5 \%)$ of patients issued anticipatory medications, requests for prescriptions came from clinicians different to the prescriber: specialist palliative care team members (42/167, 25.1\%), community nurses (20/167, 12\%); GP practice-based paramedics (3/167, $1.8 \%)$; care home staff (2/167, $1.2 \%)$. GPs in all eleven GP practices $(37 / 167,22.2 \%)$ prescribed anticipatory medications following requests from specialist palliative care or community nurse colleagues without recorded contact with the patient or family.

The majority of anticipatory medications (127/167, $76 \%)$ were prescribed by GPs: other prescribers included hospital doctors $(25 / 167,15 \%)$, nurse prescribers (7/167, $4.2 \%)$, out of hours doctors $(6 / 167,3.6 \%)$ and specialist palliative care doctors $(2 / 167,1.2 \%)$.

\section{Symptom control prescribing}

Most patients (154/167, 92.2\%) were prescribed anticipatory medications for all five common end-of-life symptoms: pain, breathlessness, nausea and vomiting, agitation and respiratory tract secretions. Similar drugs and dose ranges were prescribed for all five symptoms following end-of-life electronic record template recommendations for $105 / 167$ (62.9\%) of patients. See Table 4.

\section{Anticipatory syringe drivers (pumps)}

For 49/167 (29.3\%) of patients, a prescription for a continuous subcutaneous infusion of end-of-life care drugs was
Table 4. Anticipatory medications prescribed.

\begin{tabular}{|c|c|c|}
\hline Drug group and name & $n$ & Percentage (\%) \\
\hline Opioid & 165 & 98.8 \\
\hline Morphine Sulfate ${ }^{b}$ & 114 & 68.3 \\
\hline Oxycodone $e^{b}$ & 26 & 15.6 \\
\hline Diamorphine $^{b}$ & 25 & 15.0 \\
\hline Anxiolytic & 166 & 99.4 \\
\hline Midazolama & 166 & 99.4 \\
\hline Anti-emetic & 159 & 95.2 \\
\hline Haloperidolc & 97 & 58.0 \\
\hline Cyclizine $^{c}$ & 54 & 32.3 \\
\hline Levomepromazine $^{c}$ & 5 & 3.0 \\
\hline Metoclopramide ${ }^{c}$ & 2 & 1.2 \\
\hline Ondansetron ${ }^{c}$ & 1 & 0.6 \\
\hline Antisecretory & 163 & 97.6 \\
\hline Glycopyrronium $^{d}$ & 152 & 91.0 \\
\hline Hyoscine Butylbromide ${ }^{d}$ & 9 & 5.4 \\
\hline Hyoscine hydrobromide ${ }^{d}$ & 2 & 1.2 \\
\hline
\end{tabular}

The sample size was 167 for all drug groups. Recorded reason for prescription:

aRestlessness or agitation.

bPain relief and shortness of breath.

cNausea and vomiting.

${ }^{\mathrm{d}}$ Respiratory tract secretions.

also issued ahead of need. These 'anticipatory syringe drivers' were usually for the same medications as anticipatory medication injections, often with larger dose ranges. The frequency and timing of anticipatory syringe driver prescriptions varied widely between GP practices, ranging from $1 / 16$ patients $(6.3 \%)$ to $10 / 14$ patients $(71.4 \%)$, with prescribing timing a median of 5.5 days before death across the eleven GP practices (range 2-27 days). See Table 5.

\section{Discussion}

Our study is the first to highlight the high frequency and standardised prescribing of anticipatory medication prescriptions for terminally ill patients in a primary care 
Table 5. Timing of anticipatory syringe driver prescribing in days before death.

\begin{tabular}{|c|c|c|c|c|c|}
\hline $\begin{array}{l}\text { GP practice } \\
\text { ID no. }\end{array}$ & $n$ & Minimum & Maximum & Median & IQR \\
\hline One & $3 / 13$ & 6 & 94 & 27 & - \\
\hline Two & $10 / 14$ & 2 & 46 & 5.5 & $2.75-24.5$ \\
\hline Three & $7 / 14$ & 1 & 18 & 2 & $2-9$ \\
\hline Four & $4 / 28$ & 1 & 164 & 19.5 & $1.5-132$ \\
\hline Five & $4 / 19$ & 1 & 36 & 2.5 & $1.25-27.75$ \\
\hline Six & $3 / 16$ & 0 & 17 & 4 & - \\
\hline Seven & $1 / 16$ & 2 & 2 & 2 & - \\
\hline Eight & $4 / 14$ & 1 & 18 & 10.5 & $2-17.5$ \\
\hline Nine & $3 / 13$ & 1 & 49 & 16 & - \\
\hline Ten & $2 / 7$ & 4 & 5 & 4.5 & - \\
\hline Eleven & $8 / 13$ & 2 & 536 & 15 & 3.5-102 \\
\hline
\end{tabular}

population. The range of timing of prescribing identified contrasts with the published evidence reporting that prescribing is limited to a few days to several weeks before death. ${ }^{19,20}$ Our findings correspond with GPs' and nurses' accounts of preferring to put anticipatory medications in place as early as is feasible to help manage any distressing symptoms in the final days of life. ${ }^{15,21,22}$

Prognostication is a very inexact science. It is difficult to predict the timing of death ${ }^{34-37}$ particularly for those with a highly unpredictable chronic frailty dying trajectory. ${ }^{20,38,39}$ Although anticipatory medications are typically prescribed closer to death for patients with non-cancer conditions, ${ }^{19}$ six of the seven patients in our study issued a prescription a year or more before death had non-cancer diagnoses. Some patients were prescribed anticipatory medications alongside antibiotics when there was clinical uncertainty about whether they were dying or had reversible infections. The prescribing of anticipatory medications can be perceived as an unwelcome reminder of death. ${ }^{15,22}$ The presence of the drugs in the home is also used by some visiting clinicians who are unfamiliar with the patient as a signal that care should focus on last days of life symptom control, ${ }^{22}$ even when this may not yet be the case.

Anticipatory syringe driver prescribing was common practice in several of the study GP practices. The recent Gosport War Memorial Hospital inquiry in the UK has highlighted the dangers for patient safety when prescribing anticipatory syringe drivers with large dose ranges to be started at the discretion of third parties whose clinical assessment skills are unknown to the prescriber., ${ }^{7,40}$ The inquiry found that at least 456 patients died where opioids had been prescribed often with the clinical instruction 'please make comfortable'. These drugs were then administered in unjustified doses, commonly via syringe drivers. ${ }^{40,41}$ There is no previously published research on the practice of prescribing anticipatory syringe drivers: research is urgently needed to investigate the clinical appropriateness and safety of anticipatory syringe driver prescribing. ${ }^{41}$
Palliative care teams often initiate end-of-life care planning interventions including anticipatory medication prescription requests. ${ }^{15,17,42}$ Patients who had seen a specialist palliative care team were seven times more likely to be prescribed anticipatory medications. A referral to specialist palliative care, or the involvement of such a team, may again be perceived to be a signal to everyone involved that the patient is approaching end of life, which at times may not be the case.

End-of-life care planning is presented in current policy and clinical discourse as an evolving and individualised process that is started with patients whilst their condition is stable, with regular reviews as their situation and preferences change.8,43-46 In keeping with previous research, we found advance care planning decisions were frequently recorded as part of one main end-of-life care consultation or crisis intervention that comprises identifying preferred place of death, putting in place anticipatory medications and completing a DNACPR form. ${ }^{22,47,48}$ Primary care electronic end-of-life record templates, increasingly used to coordinate care across different services, aid communication and continuity of care. ${ }^{26,37,49}$ This technology also shapes practice and may inadvertently encourage the bureaucratisation of end-of-life care planning interventions by promoting a 'one size fits all' process. $22,32,50,51$ There is a tension between using templates to provide standardised guidance whilst promoting personalised care.

The preferences of clinicians and expectations of policymakers for ensuring that end-of-life advance care plans, including anticipatory medications, are in place, need to be balanced with patient and family readiness to have sensitive discussions and to make plans for future care.,84,47 Our analysis found clinical records were largely silent about conversations with patients and family members concerning the implications and emotional impacts of anticipatory medication prescribing. Corresponding with previous research, there were occasions where professional led endof-life planning, including the prescribing of anticipatory medications, took place without consultation with patients unwilling or unable to consider future care. ${ }^{22,47,48}$ Patient and family preferences for involvement in anticipatory medication prescribing decision-making, and their experiences of care, warrant urgent investigation. $7,22,52$

\section{Strengths and limitations}

Caution is needed in interpreting what records can tell us about patient and family participation in prescribing decisions. Records only contain a small part of any clinical encounter, the emphasis frequently being on clinical decisions and prescribing matters. ${ }^{32}$ The lack of recorded information on patient and family understanding of anticipatory medications and their preferences is problematic in clinical practice as records are considered authoritative and influence subsequent care decisions. ${ }^{31,32}$ The research 
methods provide limited insights into patients' and families' perspectives and highlight that these are important aspects to explore. We have recently completed in-depth longitudinal interviews exploring patients', families and their clinicians' involvement in anticipatory medication decision-making (manuscript in preparation).

The generalisability of the results is enhanced by the identification of sequential deaths and purposive sampling of GP practices and community nursing services to obtain a maximum diversity sample of team cultures and practices. ${ }^{28,29,53}$ Rich descriptions of practice aid understanding and transferability of our results. ${ }^{53}$ Our methods enabled detailed qualitative and quantitative analysis of recorded events and their context, which would not have been possible through analysis of the available large primary care datasets. $26,49,54$ Anticipatory medication prescribing data, context and decision-making are not routinely recorded in a way which is systematically retrievable by using electronic algorithms. Consequently, details of care in the body of free text records are often overlooked in large database studies and valuable insights into practice are missed. 26,54

We collected complete data from patient electronic clinical records: five patient community nursing paper prescription charts were missing. Prescribing events and contexts were confirmable from electronic records, and we present a full data set for all the variables analysed. As clinical records are not designed to collect research data, some patient characteristics were not routinely recorded. These include socioeconomic status, cohabitation status or perceived risks of opioids being misused or diverted, factors that may influence anticipatory medication prescribing. ${ }^{20}$ Data concerning the administration of anticipatory medications for these patients will be presented in a forthcoming paper.

\section{Conclusions}

This mixed-methods clinical records study provides valuable insights into an important area of community end-oflife care practice. Standardised anticipatory medication prescribing patterns suggest undue reliance on electronic end-of-life care templates and a lack of individualised prescribing as advocated in international policy. Marked variability in the timing of prescriptions, at times many months before death, underscores the challenge of prognostication and highlights the risks involved in putting medication in place too far in advance of possible need. The presence of anticipatory medications for long periods of time, or when situations are uncertain, may therefore compromise patient safety unless robust systems are in place to review their continued appropriateness and safe use.

\section{Acknowledgements}

The authors would like to thank the Positive Ageing PPI Group, Cambridge Palliative and End of Life Care PPI Group for their helping planning the study and interpreting the findings. James Brimicombe, Senior Data Manager for the Primary Care Unit, Department of Public Health and Primary Care, University of Cambridge, for his help in planning and running this study. Angela Harper for her administrative support. Efthalia (Lina) Massou, Statistician and Research Associate, for her statistical support. The National Institute for Health Research Clinical Research Network (NIHR CRN) for their study support. Hertfordshire Community NHS Trust and the other research sites for providing access to patient records.

\section{Declaration of conflicting interests}

The author(s) declared no potential conflicts of interest with respect to the research, authorship, and/or publication of this article.

\section{Funding}

The author(s) disclosed receipt of the following financial support for the research, authorship, and/or publication of this article: $\mathrm{BB}$ is funded by the National Institute for Health Research (NIHR) School for Primary Care Research. SB is supported by the NIHR Applied Research Collaboration East of England (ARC EoE) programme. This work was also supported by the RCN Foundation Professional Bursary Scheme [grant number 20181113]. The views expressed are those of the authors and not necessarily those of the NIHR or the Department of Health and Social Care.

\section{Author Contributions}

BB, KP and SB designed the study. BB carried out the analysis with input from KP and $\mathrm{SB}$. All authors contributed to the interpretation of the results and the writing of the manuscript. $B B$ is the guarantor. The corresponding author attests that all listed authors meet authorship criteria and that no others meeting the criteria have been omitted. The lead author (BB) affirms that the manuscript is an honest, accurate and transparent account of the study being reported.

\section{ORCID ID}

Ben Bowers (ID https://orcid.org/0000-0001-6772-2620

\section{Data sharing}

The anonymised prescribing quantitative data used in this study may be requested by researchers through contacting the lead author (BB) and on completion of a data use agreement.

\section{Supplemental material}

Supplemental material for this article is available online.

\section{References}

1. Terry W, Olson LG, Wilss L, et al. Experience of dying: concerns of dying patients and of carers. Intern Med J 2006; 36(6): 338-346.

2. Gott M, Small N, Barnes S, et al. Older people's views of a good death in heart failure: implications for palliative care provision. Soc Sci Med 2008; 67(7): 1113-1121.

3. Lindqvist $O$, Lundquist $G$, Dickman $A$, et al. Four essential drugs needed for quality care of the dying: a Delphi-study 
based international expert consensus opinion. J Palliat Med 2013; 16(1): 38-43.

4. Ellershaw J, Smith C, Overill S, et al. Care of the dying: setting standards for symptom control in the last 48 Hours of life. J Pain Symptom Manag 2001; 21(1): 12-17.

5. Mehta A, Chan LS and Cohen SR. Flying blind: sources of distress for family caregivers of palliative cancer patients managing pain at home. J Psychosoc Oncol 2014; 32(1): 94-111.

6. Kamphausen A, Roese $\mathrm{H}$, Oechsle $\mathrm{K}$, et al. Challenges faced by prehospital emergency physicians providing emergency care to patients with advanced incurable diseases. Emerg Med Int 2019; 2019: 3456471.

7. Bowers B, Ryan R, Kuhn I, et al. Anticipatory prescribing of injectable medications for adults at the end of life in the community: a systematic literature review and narrative synthesis. Palliat Med 2018; 33(2): 160-177.

8. National Institute for Health and Care Excellence. Care of dying adults in the last days of life: NG31. London: National Institute for Health and Care Excellence, 2015. http:// www.nice.org.uk/guidance/ng31/evidence/full-guideline-2240610301

9. Healthcare Improvement Scotland. Scottish palliative care guidelines: anticipatory prescribing, 27 April 2020. www. palliativecareguidelines.scot.nhs.uk/guidelines/pain/ Anticipatory-Prescribing.aspx

10. Staats $\mathrm{K}$, Tranvåg $\mathrm{O}$ and Grov EK. Home-care nurses' experience with medication kit in palliative care. J Hosp Palliat Nurs 2018; 20(6): E1-E9.

11. Wowchuk SM, Wilson EA, Embleton L, et al. The palliative medication kit: an effective way of extending care in the home for patients nearing death. J Palliat Med 2009; 12(9): 797-803.

12. Ministry of Health. Te Ara Whakapiri: principles and guidance for the last days of life. 2nd ed. 2017. https://www. health.govt.nz/system/files/documents/publications/ te-ara-whakapiri-principles-guidance-last-days-of-lifeapr17.pdf

13. Khalil H, Garett M, Byrne A, et al. Mapping end-of-life and anticipatory medications in palliative care patients using a longitudinal general practice database. Palliat Support Care. Epub ahead of print 10 March 2021. DOI: 10.1017/ S1478951521000092.

14. Wilson E, Morbey $\mathrm{H}$, Brown J, et al. Administering anticipatory medications in end-of-life care: a qualitative study of nursing practice in the community and in nursing homes. Palliat Med 2015; 29(1): 60-70.

15. Bowers B and Redsell SA. A qualitative study of community nurses' decision-making around the anticipatory prescribing of end-of-life medications. J Adv Nurs 2017; 73(10): 2385-2394.

16. Kemp L, Holland R, Barclay $\mathrm{S}$, et al. Pre-emptive prescribing for palliative care patients in primary care. BMJ Support Palliat Care 2012; 2(Suppl 1): A2.1-A2.

17. Brewerton H, May A and Cox L. P-111 the practice of requesting anticipatory medications for use at the end of life in patients referred to a community palliative care service, a retrospective notes review. BMJ Support Palliat Care 2015; 5(Suppl 3): A39.3-A39.
18. Lawton S, Denholm M, Macaulay L, et al. Timely symptom management at end of life using 'just in case' boxes. $\mathrm{Br} \mathrm{J}$ Commun Nurs 2012; 17(4): 182-183, 186, 188.

19. Rainbow E and Faull C. P-120 describing anticipatory medicine use in the community at the end of life. BMJ Support Palliat Care 2017; 7: A52.

20. Faull C, Windridge K, Ockleford E, et al. Anticipatory prescribing in terminal care at home: what challenges do community health professionals encounter? BMJ Support Palliat Care 2013; 3: 91-97.

21. Perkins $E$, Gambles $M$, Houten R, et al. The care of dying people in nursing homes and intensive care units: a qualitative mixed-methods study. Health Serv Deliv Res 2016; 4(20): 1-410.

22. Bowers B, Barclay SS, Pollock K, et al. General practitioners' decisions about prescribing end-of-life anticipatory medications: a qualitative study. Br J Gen Pract 2020; 70(699): e731-e739.

23. Wilson E, Seymour J and Seale C. Anticipatory prescribing for end of life care: a survey of community nurses in England. Prim Health Care 2016; 26(9): 22-27.

24. Wilson E and Seymour J. The importance of interdisciplinary communication in the process of anticipatory prescribing. Int J Palliat Nurs 2017; 23(3): 129-135.

25. Griggs $\mathrm{C}$. Community nurses' perceptions of a good death: a qualitative exploratory study. Int J Palliat Nurs 2010; 16(3): 140-149.

26. Stow D, Matthews FE and Hanratty B. Timing of GP endof-life recognition in people aged $\geqslant 75$ years: retrospective cohort study using data from primary healthcare records in England. Br J Gen Pract 2020; 70(701): e874-e879.

27. Lawton J. Gaining and maintaining consent: ethical concerns raised in a study of dying patients. Qual Health Res 2001; 11(5): 693-705.

28. Charmaz K. Constructing grounded theory: a practical guide through qualitative analysis. London: SAGE, 2006.

29. Vassar M and Holzmann M. The retrospective chart review: important methodological considerations. J Educ Eval Health Prof 2013; 10(12): 12.

30. Berger $\mathrm{P}$ and Luckman T. The social construction of reality: a treatise in the sociology of knowledge. Harmondsworth: Penguin Books, 1966.

31. Diamond T. Making Gray gold: narratives of nursing care. Chicago, IL: The University of Chicago Press, 1992.

32. Sheaff R, Halliday J, Byng R, et al. Bridging the discursive gap between lay and medical discourse in care coordination'. Sociol Health IIIn 2017; 39(7): 1019-1034.

33. Mauthner NS and Doucet A. Reflexive accounts and accounts of reflexivity in qualitative data analysis. Sociology 2003; 37(3): 413-431.

34. White N, Kupeli N, Vickerstaff V, et al. How accurate is the "surprise question" at identifying patients at the end of life? A systematic review and meta-analysis. BMC Med 2017; 15(1): 139.

35. Downar J, Goldman R, Pinto R, et al. The "surprise question" for predicting death in seriously ill patients: a systematic review and meta-analysis. Can Med Assoc J 2017; 189(13): E484-E493. 
36. Barclay S, Froggatt $\mathrm{K}$, Crang $\mathrm{C}$, et al. Living in uncertain times: trajectories to death in residential care homes. $\mathrm{Br} J$ Gen Pract 2014; 64(626): e576-e583.

37. Alcorn G, Murray SA and Hockley J. Care home residents who die in hospital: exploring factors, processes and experiences. Age Ageing 2020; 49(3): 468-480.

38. Pollock K and Seymour J. Reappraising 'the good death' for populations in the age of ageing. Age Ageing 2018; 47(3): 328-330.

39. Murray SA, Kendall M, Boyd K, et al. Illness trajectories and palliative care. BMJ 2005; 330(7498): 1007-1011.

40. Gosport Independent Panel. Gosport War Memorial Hospital: the report of the Gosport Independent Panel. 20 June 2018. https://www.gosportpanel.independent.gov.uk/media/documents/070618_CCS207 CCS03183220761_Gosport_Inquiry_Whole_Document.pdf

41. Bowers B, Ryan R, Hoare S, et al. Anticipatory syringe drivers: a step too far. BMJ Support Palliat Care 2019; 9(2): 149-150.

42. Lovell A and Yates P. Advance care planning in palliative care: a systematic literature review of the contextual factors influencing its uptake 2008-2012. Palliat Med 2014; 28(8): 1026-1035.

43. NHS Improving Quality. Capacity, care planning and advance care planning in life limiting illness a guide for health and social care staff. 2014. https://www.england.nhs.uk/improvement-hub/wp-content/uploads/ sites/44/2017/11/ACP_Booklet_2014.pdf

44. National Palliative and End of Life Care Partnership. Ambitions for palliative and end of life care: a national framework for local action 2015-2020. 2015. https:// www.nationalvoices.org.uk/sites/default/files/public/ publications/ambitions-for-palliative-and-end-of-lifecare.pdf
45. Sharp T, Malyon A and Barclay S. GPs' perceptions of advance care planning with frail and older people: a qualitative study. Br J Gen Pract 2018; 68(666): e44-e53.

46. Herrmann A, Carey M, Zucca A, et al. General practitioners' perceptions of best practice care at the end of life: a qualitative study. BJGP Open 2019; 3(3): 1-11. DOI: 10.3399/ bjgpopen19X101660.

47. Pollock K and Wilson E. Care and communication between health professionals and patients affected by severe or chronic illness in community care settings: a qualitative study of care at the end of life. Health Serv Deliv Res 2015; 3(31): 1-138.

48. Deckx L, Mitchell G, Rosenberg J, et al. General practitioners' engagement in end-of-life care: a semi-structured interview study. BMJ Support Palliat Care. Epub ahead of print 3 September 2019. DOI: 10.1136/bmjspcare-2019-001817.

49. Allsop MJ, Kite $S$, McDermott $S$, et al. Electronic palliative care coordination systems: devising and testing a methodology for evaluating documentation. Palliat Med 2017; 31(5): 475-482.

50. Mol A. The logic of care: health and the problem of patient choice. London: Routledge, 2008.

51. Seymour J, Almack K and Kennedy S. Implementing advance care planning: a qualitative study of community nurses' views and experiences. BMC Palliat Care 2010; 9(4): 4.

52. Payne $S$, Turner $M$, Seamark $D$, et al. Managing end of life medications at home-accounts of bereaved family carers: a qualitative interview study. BMJ Support Palliat Care 2015; 5(2): 181-188.

53. Lincoln $\mathrm{Y}$ and Guba E. Naturalistic inquiry. London: SAGE, 1985.

54. Agniel D, Kohane IS and Weber GM. Biases in electronic health record data due to processes within the healthcare system: retrospective observational study. BMJ 2018; 361: k1479. 